\title{
Noise level and annoyance of Industrial factories in Duhok city
}

\author{
Berivan H. M. Al-Dosky \\ Branch of Basic Sciences, School of plant production, faculty of Agriculture and forestry, Duhok University, \\ Kurdistan Region, Iraq
}

\begin{abstract}
Noise pollution is considered as more important environmental problem, especially in the industrialized and developed countries. Industrial noise is an important source of noise pollution, which annoys and disrupts the daily activities of workers. This study focuses on the industrial noise and its effects on workers. Thirteen different industries chosen randomly in Duhok city, in Kurdistan region, North of Iraq. To cover this study an instrument for measurement the sound level was used, in addition to a questionnaire contains (38) questions to study all the possible reported effects of noise on humans, (90) workers of different industries were chosen, the questionnaires were analysis to determine how much employees were affected by high noise levels in the workplace.

During the survey, it has been specified that all industries noise levels measurement are much above the maximum (OSHA) exposure limits. $81.11 \%$ of workers are annoyed from the noise in their workplaces. To determine whether the effects of noise were statistically significant or not, a Chi-Square test was used. At a level of significance, $p \leq 0.05$, a relationship between duration of employment years and feeling annoyed are statistically significant. It was found that the physiological and psychological effects of noise i.e. headache, disturbs their peace of mind, nervousness, stressful, speech interference and insomnia are statistically significant. However, dizziness is statistically not significant. $65.56 \%$ of respondents in these industries are suffering from hearing problems, $34.44 \%$ of them have complaints about ringing in ears and only $10 \%$ of workers were used EPE.
\end{abstract}

Keywords: Industrial noise, noise effect, annoyance, social survey, psychological effects, physiological effects

\section{Introduction}

The sound is a mechanical wave that results from variations, or oscillations, in elastic medium like water, air and solids and "Noise" generally can be defined as unpleasant and disturbing sounds which disturb the human being physically and physiologically and cause environmental pollution by destroying environmental properties $[1,2,3,4,5]$ and it is one of the physical environmental factors affecting our health in today's world and harmful to people. Noise can be measured by determining the pressure created by the sound waves in the human ear and is measured in $(\mathrm{dB})$, which is used as an international measure of the intensity of sound.

Due to the rapid growth and development in technology which is occurred in the developing countries, noise pollution has become one of the major threats that face the environment and the cost of reducing it in future years is expected to be insurmountable [6] and it is considered to be the commonest reason of annoyance and permanent hearing loss [1].

One of the important problems of noise sources is industrial noise. The general effect of industrial noise on the health of workers has been a topic of debate among scientists for a number of years $[7,8,9]$. The large, medium and small scale hand tool manufacturers of developing countries are lagging far behind in implementing hearing conservation, noise control programs, occupational health and safety programs. These industries have a plenty of devices and machines that considered as a source of noise such as: rotors, cutting machines, motors, compressors, electrical machines, internal combustion engines, drilling, crushing, fans and transportation resources. The noise level generated depends mainly on the type of the noise source such as the kinds of machines, distance from the source to the employee or receiver and the nature of the working environment. Consequently the workers of hand tool industrial are exposed to the noise levels overstep the permissible limits. High noise exposure in industries not only affects the communication among the workers, but also leads to the other psychological and physiological effects on the workers.

At the recent past ten year the overall loudness of environmental noise is doubled, so that serious attention must be given to control this growing problem [10]. Hence scientists attempt to discuss and study occupational noise exposure in different fields and the effects of noise pollution on human's health. Several noise surveys treating the problem of noise pollution in many countries throughout the world have been conducted $[11,12,13,14,15,16,17,18,19]$. Most of these researches have been concentrated with the effect of noise on the auditory system, such as temporary or permanent hearing loss [20,21,22], and it is now well established that exposure to noise levels of relatively high degrees can lead to direct hearing loss and / or hearing impairment [23]. However, more recent researches have concentrated on the relationship between noise 
and non-auditory impacts [24]. Social survey data has shown that annoyance, speech interference, sleep disturbance or insomnia and cardiovascular problems are considered to be the most important environmental noise effects $[25,26]$.

The aim of the present study was to carry out measurements to evaluate industrial noise levels, to see that if these levels exceeded the permissible levels set by the Occupational Safety and Health Administration (OSHA) that protect public health of workers, and to assess the noise pollution and its effects on the psychological and physiological reactions and annoyance response of workers.

The material and method adopted for this study are described. Results and discussion are highlighted, and the important points of this study are mention in conclusion.

\section{Materials and Methods}

This study includes the measurement of noise and a questionnaire based survey.

\section{Industrial samples}

This study has been carried out in thirteen different size industries spread through Duhok city. The industries have been classified into seven groups based on products such as: metal or mourning, joiner or carpenter, aluminum, auto mechanic, washing carpet, printing house and tailor (Table 1). This study was conducted between September and November 2013.

\section{Workers samples}

The current study was conducted on a group of workers who worked in thirteen various types of factories distributed in several locations in Duhok city. The samples of this study were ninety workers, distributed in these different factories or industries (Table 1). Daily working hours are between (4-12h/d), workers are given (1h) lunch break excluding the work time of $(8-12 \mathrm{~h} / \mathrm{d})$. The sample's ages were between (1455) years.

\section{Questionnaire or social survey}

Employee surveys were distributed to thirteen industrial sites. The questionnaire for the survey comprised of (38) question contained questions about gender, age, education level, knowledge of noise exposure, knowledge of hearing protection, knowledge of protection them self, physiological and psychological effects, maximum daily and year exposure duration. Physiological and psychological equations are about annoyance, headache, dizziness, disturbs their peace of mind, nervousness, stressful, speech interference, insomnia, ringing in ears and pain or harm in the ears. Each question was provided with five choices of responses, i.e. always, often, sometime, seldom and never. The other questions were having yes or no response.

\section{Measurement of sound pressure levels in industries}

The measurement of industrial noise was carried out by author at investigation areas. The chosen locations represented all types of industrial work place. The measurement time interval was adjusted for (15min)[27] each time on each work section. A sound pressure level meter measuring instrument Model SL-200 (VOLTCRAFT) was used in these measurements, it is designed to approximate the loudness level sensitivity of the human ear. Measurements results have been recorded by holding the instrument at a height equal to the ear level of the workers and sound pressure level was recorded at least five times in different locations where the workers actually work or movement of the workers was most frequent in order to determine the noise levels to which the workers are exposed. Measurements were carried out for every kind of industries for all hours of working.

\section{Statistical analysis}

All questionnaires and collected data were recorded as Microsoft Excel 2010. Statistical Package for Social Scientists (SPSS) and Chi-square was used for analysis to determine whether the effects of noise on workers are significant or not. 


\subsection{Noise levels measurements}

\section{Results and Discussion}

The number of industries, the results of the noise level ranges measurements during all working hours in all kinds of industries and the number of workers who responded to the survey from each industry are shown in (Table 1). This table also shows the percentage of respondent from each factory and mean value of noise level.

Table 1: Industrial noise measurement results in $\mathrm{dB}(\mathrm{A})$ and number of workers.

\begin{tabular}{|c|c|c|c|c|c|c|}
\hline Industrial group & $\begin{array}{l}\text { Number of } \\
\text { Industrial }\end{array}$ & $\begin{array}{l}\text { Name of } \\
\text { Industrial }\end{array}$ & $\begin{array}{c}\text { Number of } \\
\text { workers }\end{array}$ & $\begin{array}{c}\text { Sample } \\
\text { percentage } \\
(\%)\end{array}$ & $\begin{array}{l}\text { Noise level } \\
\text { rang } d B(A)\end{array}$ & $\begin{array}{c}\text { Mean value } \\
\text { of noise } \\
\text { level dB(A) }\end{array}$ \\
\hline \multirow{2}{*}{$\begin{array}{l}\text { Metal or } \\
\text { Mourning }\end{array}$} & 1 & $\mathrm{M}_{1}$ & 3 & 3.33 & $94.8-104$ & 99.21 \\
\hline & 2 & $\mathrm{M}_{2}$ & 8 & 8.89 & $90.5-102$ & 97.25 \\
\hline \multirow{3}{*}{ Joiner } & 1 & $\mathrm{~J}_{1}$ & 4 & 4.44 & $89.1-95.1$ & 92.88 \\
\hline & 2 & $\mathrm{~J}_{2}$ & 5 & 5.56 & $95.6-110$ & 101.35 \\
\hline & 3 & $\mathrm{~J}_{3}$ & 20 & 22.22 & $72.3-92.8$ & 82.24 \\
\hline \multirow{3}{*}{ Aluminum } & 1 & $\mathrm{~A}_{1}$ & 2 & 2.22 & $88-98$ & 92.15 \\
\hline & 2 & $\mathrm{~A}_{2}$ & 4 & 4.44 & $99.4-115.9$ & 105.9 \\
\hline & 3 & $\mathrm{~A}_{3}$ & 6 & 6.67 & $98.5-107.1$ & 101.05 \\
\hline \multirow{2}{*}{ Auto Mechanic } & 1 & $\mathrm{AM}_{1}$ & 2 & 2.22 & $88-102$ & 94.61 \\
\hline & 2 & $\mathrm{AM}_{2}$ & 3 & 3.33 & $89.4-123.6$ & 111.01 \\
\hline Washing Carpet & 1 & WC & 6 & 6.67 & $90.8-110$ & 101.22 \\
\hline Printing House & 1 & $\mathrm{PH}$ & 20 & 22.22 & $77.3-99.1$ & 87.72 \\
\hline $\begin{array}{c}\text { Tailor or } \\
\text { Dressmaker }\end{array}$ & 1 & $\mathrm{~T}$ & 7 & 7.78 & $78.5-88.3$ & 82.74 \\
\hline
\end{tabular}

Results shows that majority of industries have high noise level. In larger, medium and small size industries, the major source of noise is from industrial machines. The workers who operate these machines are significantly exposed to high noise levels compared to other workers that they not operate it, the majority of workers are machine operators and because the size of many factories are not large noise exposure was not limited to machine operators, sound pressure levels are approximately equal in all locations except in the joiner $\left(\mathrm{J}_{3}\right)$ and printing house factories sound pressure levels are not equal in all locations because the size of both industries are larger than other factories, old machines are responsible for most of the noises. Our survey included questions on daily working hours and total machine operation time or daily exposure hours to high noise levels in order to accurately assess duration of employee noise exposure. $93.34 \%$ of workers operated $8 \mathrm{~h} / \mathrm{d}$ and more than $8 \mathrm{~h} / \mathrm{d}$ in six d/wk i.e. operating time is $48 \mathrm{~h} / \mathrm{wk}$ as shown in (Table 2 ). The workers daily exposure hours were between $1-12 \mathrm{~h} / \mathrm{d}$ as shown in (Table 2).

The Occupational Safety and Health Administration (OSHA) specify a legal limit on noise exposure in the workplace. It put the occupational noise standards to protect humans health [28,29]. By comparing (OSHA) law with actual maximum daily exposure duration to industrial noise, it can be observed from (Table1 and 2) that the majority of the study has level values that don't correspond with working hours per day as the (OSHA) illustrated. It was observed in case of noise level $115 \mathrm{~dB}(\mathrm{~A})$, the maximum daily exposure duration set by (OSHA) is $0.25 \mathrm{~h} / \mathrm{d}$ or less but workers perform $2 \mathrm{~h} / \mathrm{d}$ in auto mechanic and exposure to $123.6 \mathrm{~dB}(\mathrm{~A})$ noise. In many factories, the workers perform $8 \mathrm{~h} / \mathrm{d}$ in noise level $100 \mathrm{~dB}(\mathrm{~A})$, but maximum daily exposure duration to $100 \mathrm{~dB}(\mathrm{~A})$ noise set by (OSHA) is $2 \mathrm{~h} / \mathrm{d}$. In case of noise level $95 \mathrm{~dB}(\mathrm{~A})$, the maximum daily exposure duration sets by (OSHA) is $4 \mathrm{~h} / \mathrm{d}$ but workers perform $8 \mathrm{~h} / \mathrm{d}$ in noise level $95 \mathrm{~dB}(\mathrm{~A})$ and greater than $95 \mathrm{~dB}(\mathrm{~A})$ as shown in (Table 1). This means that maximum daily exposure duration which set by (OSHA) to protect health of workers was not taken in consideration for any level of industrial noise in Duhok city factories. For long duration 10-15 years, exposure to high intensity noise in 6-8 h/d can cause biochemical changes which make the workers prone to cardiovascular pathology, depression and other psychological conditions [30,31].

Table 2: Workers daily working hours and daily exposure hours.

\begin{tabular}{|c|c|c|c|}
\hline Daily working hours & Percentage \% & Daily exposure hours & Percentage \% \\
\hline- & - & $1 \mathrm{~h}-3 \mathrm{~h}$ & $10.00 \%$ \\
\hline $4 \mathrm{~h}-6 \mathrm{~h}$ & $6.67 \%$ & $4 \mathrm{~h}-6 \mathrm{~h}$ & $40.00 \%$ \\
\hline $8 \mathrm{~h}-9 \mathrm{~h}$ & $66.67 \%$ & $8 \mathrm{~h}-9 \mathrm{~h}$ & $35.56 \%$ \\
\hline $10 \mathrm{~h}-12 \mathrm{~h}$ & $26.67 \%$ & $10 \mathrm{~h}-12 \mathrm{~h}$ & 14.44 \\
\hline
\end{tabular}

\subsection{Questionnaire or social survey results and evaluation}

The questionnaire has been applied on (90) workers selected from all different industries. All the respondents or workers are males. Distribution of the workers has been examined according to their factories, ages, educational situation and Duration of employment. Distribution of the workers according to their 
industries is: $12.22 \%$ metal or mourning, $32.22 \%$ joiner, $13.33 \%$ aluminum, $5.56 \%$ auto mechanic, $6.67 \%$ washing carpet, $22.22 \%$ printing house and $7.78 \%$ tailor (Table 3). The workers ages were between 14 to 55 years (with mean value of 29.12 year). Ages of interviewed workers exhibit a wide range: $13.33 \%$ were $<20$ years, $21.11 \%$ were $21-25$ years, $27.78 \%$ were $26-30$ years, $17.78 \%$ were $31-35$ years, $11.11 \%$ were $36-40$ years, $7.78 \%$ were $41-50$ years and $1.11 \%$ was $>50$ (Table 3 ). Distribution of the workers according to their educational level is: $5.56 \%$ no educational, $27.78 \%$ primary school, $31.11 \%$ intermediate, $27.78 \%$ high school, $5.56 \%$ technical and $2.22 \%$ university education (Fig. 1). It has been determined that their distribution with respect to their working periods is: $36.66 \%$ were $1-5$ years, $26.67 \%$ were $6-10$ years, $15.56 \%$ were $11-15$ years, $11.11 \%$ were $16-20$ years, $5.56 \%$ were $21-25$ years, $3.33 \%$ were $26-30$ years and $1.11 \%$ more than 30 years (Table 3). When the industries, ages, education levels and working periods were compared, it has been specified that the majority of the workers were from joiner industry, age range of 26-30 years, service period range of 1-5 years and generally intermediate graduates.

Table 3: Distribution of age groups, Duration of employment years and Industries distribution groups.

\begin{tabular}{|c|c|c|c|c|c|}
\hline Age groups & $\begin{array}{c}\text { Number of } \\
\text { subjects and } \\
\text { percentage }\end{array}$ & $\begin{array}{c}\text { Duration of } \\
\text { employment } \\
\text { years }\end{array}$ & $\begin{array}{c}\text { Number of } \\
\text { subjects and } \\
\text { percentage }\end{array}$ & Industrial groups & $\begin{array}{c}\text { Number of } \\
\text { subjects and } \\
\text { percentage }\end{array}$ \\
\hline$<20$ & $12(13.33 \%)$ & $1-5$ & $33(36.66 \%)$ & Metal & $11(12.22 \%)$ \\
\hline $21-25$ & $19(21.11 \%)$ & $6-10$ & $24(26.67 \%)$ & Joiner & $29(32.22 \%)$ \\
\hline $26-30$ & $25(27.78 \%)$ & $11-15$ & $14(15.56 \%)$ & Aluminum & $12(13.33 \%)$ \\
\hline $31-35$ & $16(17.78 \%)$ & $16-20$ & $10(11.11 \%)$ & Auto Mechanic & $5(5.56 \%)$ \\
\hline $36-40$ & $10(11.11 \%)$ & $21-25$ & $5(5.56 \%)$ & Washing Carpet & $6(6.67 \%)$ \\
\hline $41-50$ & $7(7.78 \%)$ & $26-30$ & $3(3.33 \%)$ & Printing House & $20(22.22 \%)$ \\
\hline$>50$ & $1(1.11 \%)$ & $>30$ & $1(1.11 \%)$ & Tailor & $7(7.78 \%)$ \\
\hline
\end{tabular}

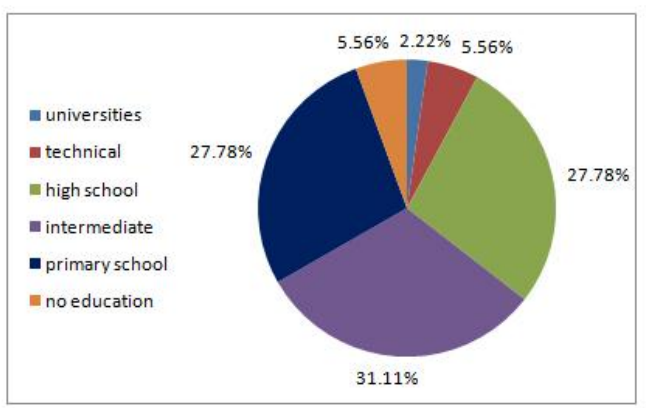

Fig. 1: Education level of workers.

\subsubsection{Noise annoyance}

$81.11 \%$ of workers were annoyed by industrial noise and $18.89 \%$ said that they are not annoyed because: (1) respondents consider that noise is result of their job and they must be patient related that matter, (2) they have accepted noise as a part of their works, and they get adapted to noisy job conditions with increasing work exposure to high noise levels. Five step semantic scale were used to respond about worker's attitudes from industrial noise [10,12]. $23.33 \%$ of the workers reported 'always' annoyed, $31.11 \%$ 'often', $21.11 \%$ 'sometimes', $5.56 \%$ of workers 'seldom annoyed' and $18.89 \%$ 'never' felt annoyed by high noise levels (Fig. 2).

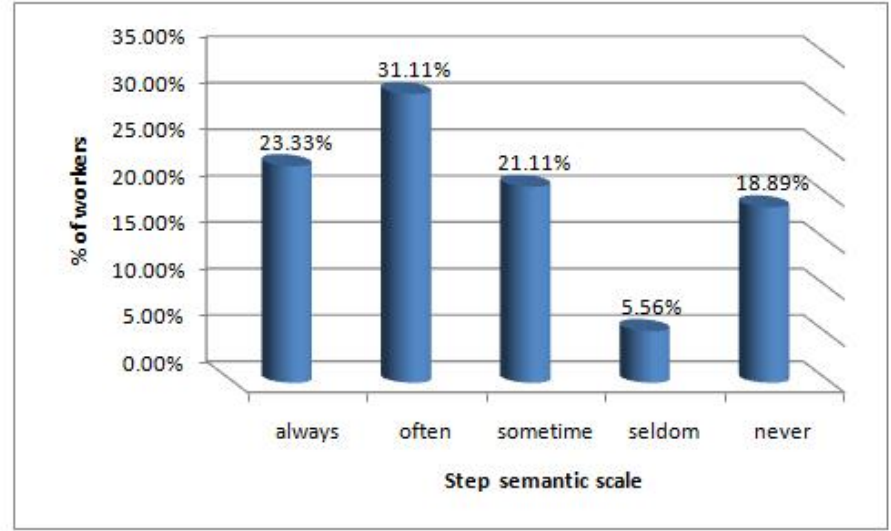

Fig. 2: Percentage distribution of noise annoyances.

By examination of the rates of disturbance in the workers depending on their duration of employment years, it has been observed that majority of the workers who reported noise annoyance were with less than and 
equal to five years of work exposure, as long as exposure increases workers get adapted to noise and noise annoyance is reduced [27] as shown in (Table 4). From Chi-square distribution [32], $\mathrm{P} \leq 0.05$ and degree of freedom (D.F) =5, the critical value of Chi-square obtain is 11.070. The Chi-square for (Table 4) is 17.407. This result shows that there is significant relationship between duration of employment years and feeling annoyance.

Table 4: The relationship between duration of employment years and annoyance of workers.

\begin{tabular}{|c|c|c|c|c|}
\hline \multirow{2}{*}{\multicolumn{2}{|c|}{$\begin{array}{c}\text { Duration of } \\
\text { employment years }\end{array}$}} & \multicolumn{3}{|c|}{ Annoyance of workers } \\
\hline & & Yes & No & Total \\
\hline \multirow{2}{*}{$1-5$} & $\mathrm{~N}$ & 30 & 3 & 33 \\
\hline & $\%$ & $90.91 \%$ & $9.09 \%$ & $36.67 \%$ \\
\hline \multirow{2}{*}{$6-10$} & $\mathrm{~N}$ & 21 & 3 & 24 \\
\hline & $\%$ & $87.50 \%$ & $12.50 \%$ & $26.67 \%$ \\
\hline \multirow{2}{*}{$11-15$} & $\mathrm{~N}$ & 12 & 2 & 14 \\
\hline & $\%$ & $85.71 \%$ & $14.29 \%$ & $15.56 \%$ \\
\hline \multirow{2}{*}{$16-20$} & $\mathrm{~N}$ & 7 & 3 & 10 \\
\hline & $\%$ & $70.00 \%$ & $30.00 \%$ & $11.11 \%$ \\
\hline \multirow{2}{*}{$21-25$} & $\mathrm{~N}$ & 2 & 3 & 5 \\
\hline & $\%$ & $40.00 \%$ & $60.00 \%$ & $5.56 \%$ \\
\hline \multirow{2}{*}{$>26$} & $\mathrm{~N}$ & 1 & 3 & 4 \\
\hline & $\%$ & $25.00 \%$ & $75.00 \%$ & $4.44 \%$ \\
\hline \multirow{2}{*}{ Total } & $\mathrm{N}$ & 73 & 17 & 90 \\
\hline & $\%$ & $81.11 \%$ & $18.89 \%$ & $100.00 \%$ \\
\hline
\end{tabular}

The results of the questionnaire interviews about psychological and physiological effects of industrial noise $[9,11]$ in seven factors, were analyzed. Analytical survey from these seven factors which are threatened the worker's health has been done. The number and percentage of these seven factors are represent clearly in (Table 5) and (Fig. 3). (Table 5 and Fig.3) display that most of responds to these seven variables was always and sometimes. $41.11 \%$ of respondents reported sometimes headache from high noise levels, $44.44 \%$ reported sometimes having dizziness during or after work due to high noise levels, $41.11 \%$ reported had disturbs their peace of mind, $47.78 \%$ reported always nervousness, 48.89 reported always feeling stressful during work in a noisy area, $35.56 \%$ reported sometime had speech interference and $43.33 \%$ reported always had insomnia.

Table 5: Annoyance factors and responds of workers

\begin{tabular}{|c|c|c|c|c|c|c|c|}
\hline \multirow{2}{*}{\multicolumn{2}{|c|}{ Annoyance factors }} & \multicolumn{6}{|c|}{ Responds } \\
\hline & & \multirow{3}{*}{$\begin{array}{c}\text { always } \\
26 \\
28.89 \% \\
\end{array}$} & \multirow{3}{*}{$\begin{array}{c}\text { often } \\
10 \\
11.11 \%\end{array}$} & \multirow{3}{*}{$\begin{array}{c}\text { sometime } \\
37 \\
41.11 \% \\
\end{array}$} & \multirow{3}{*}{$\begin{array}{c}\text { seldom } \\
4 \\
4.44 \%\end{array}$} & \multirow{3}{*}{$\begin{array}{c}\text { never } \\
13 \\
14.44 \%\end{array}$} & \multirow{3}{*}{$\begin{array}{c}\text { Total } \\
90 \\
100.00 \%\end{array}$} \\
\hline \multirow{2}{*}{ headache } & $\mathrm{N}$ & & & & & & \\
\hline & $\%$ & & & & & & \\
\hline \multirow{2}{*}{ dizziness } & $\mathrm{N}$ & 26 & 4 & 40 & 12 & 8 & 90 \\
\hline & $\%$ & $28.89 \%$ & $4.44 \%$ & $44.44 \%$ & $13.33 \%$ & $8.89 \%$ & $100.00 \%$ \\
\hline \multirow{2}{*}{$\begin{array}{l}\text { disturbs their } \\
\text { peace of mind }\end{array}$} & $\mathrm{N}$ & 23 & 12 & 37 & 4 & 14 & 90 \\
\hline & $\%$ & $25.56 \%$ & $13.33 \%$ & $41.11 \%$ & $4.44 \%$ & 15.56 & $100.00 \%$ \\
\hline \multirow{2}{*}{ nervousness } & $\mathrm{N}$ & 43 & 7 & 26 & 5 & 9 & 90 \\
\hline & $\%$ & $47.78 \%$ & $7.78 \%$ & $28.89 \%$ & $5.56 \%$ & $10.00 \%$ & $100.00 \%$ \\
\hline \multirow{2}{*}{ stressful } & $\mathrm{N}$ & 44 & 11 & 20 & 3 & 12 & 90 \\
\hline & $\%$ & $48.89 \%$ & $12.22 \%$ & $22.22 \%$ & $3.33 \%$ & $13.33 \%$ & $100.00 \%$ \\
\hline \multirow{2}{*}{$\begin{array}{c}\text { speech } \\
\text { interference }\end{array}$} & $\mathrm{N}$ & 25 & 3 & 32 & 9 & 21 & 90 \\
\hline & $\%$ & $27.78 \%$ & $3.33 \%$ & $35.56 \%$ & $10.00 \%$ & $23.33 \%$ & $100.00 \%$ \\
\hline \multirow{2}{*}{ insomnia } & $\mathrm{N}$ & 39 & 6 & 9 & 15 & 21 & 90 \\
\hline & $\%$ & $43.33 \%$ & $6.67 \%$ & $10.00 \%$ & $16.67 \%$ & $23.33 \%$ & $100.00 \%$ \\
\hline
\end{tabular}

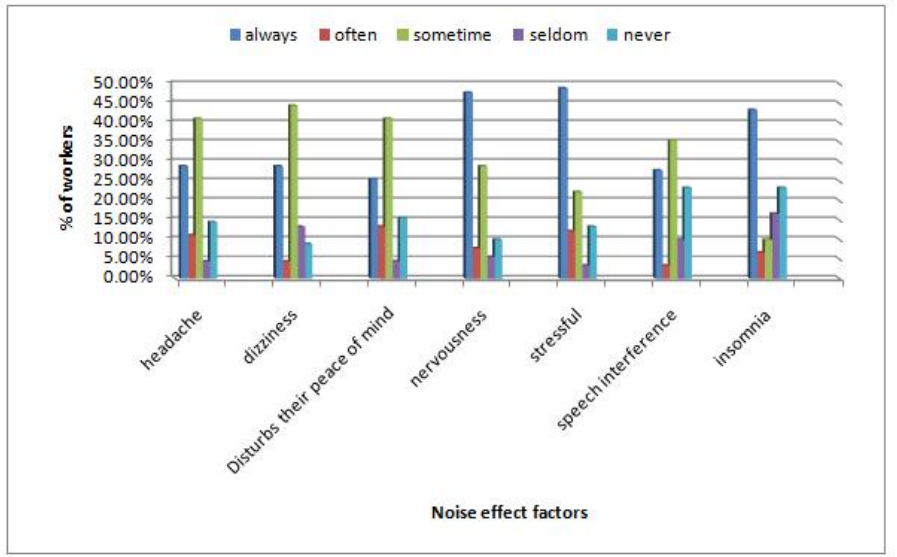

Fig. 3: Percentage distributions of noise annoyance factors.

(Fig. 4) show the relationship between effects of noise on workers in seven factors for three ranges of noise level and the percentage of the workers in five responds. This figure display that in noise level ranges 90- 
$100 \mathrm{~dB}(\mathrm{~A})$ and $>100 \mathrm{~dB}(\mathrm{~A})$ the respond never is approximately disappear in all factors that means when noise level increase the effects on the health of workers increase.

(Table 6) shows the total Chi-square value obtained from different noise level ranges and different responds. From Chi-square distribution [32], $\mathrm{P} \leq 0.05$ and degree of freedom (D.F)=8, the critical value of Chisquare obtained is 15.507. (Table 6) shows that the computerized test statistics for the effect of noise on headache, disturbs their peace of mind, nervousness, stressful, speech interference or problem in speech communication and insomnia exceeds the critical value, hence the null hypothesis is rejected. This means that there is significant relationship between this type of effects of noise on workers and the types of noise level ranges. In case of dizziness factor the null hypothesis is accepted, because the computerized test statistics for it is less than critical value so that there is no significant relationship between dizziness effect on workers and the types of noise level ranges.

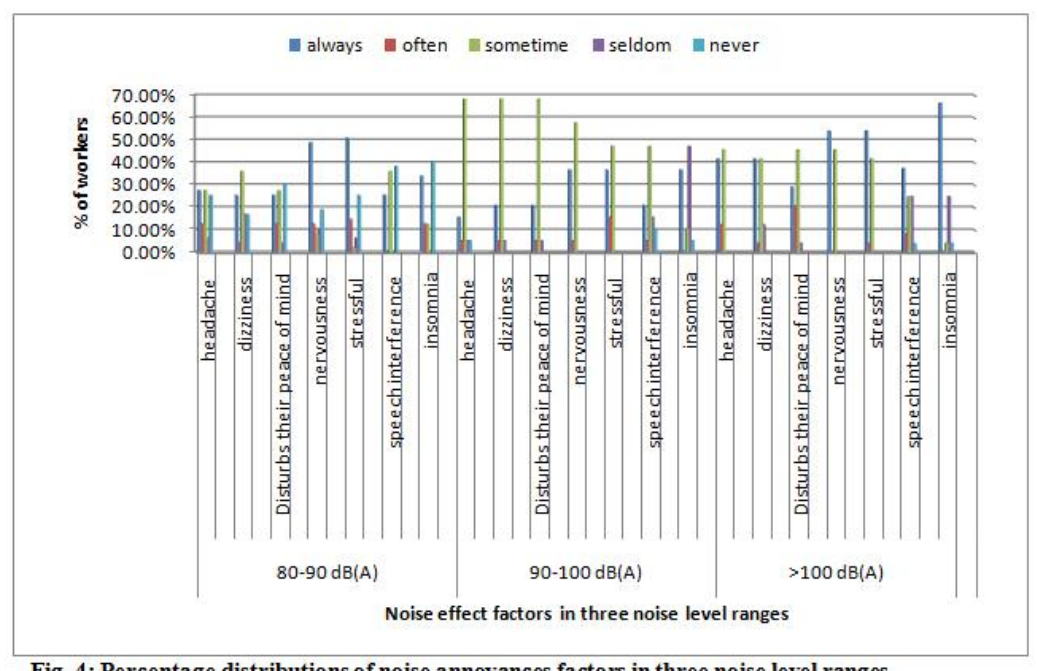

Fig. 4: Percentage distributions of noise annoyances factors in three noise level ranges.

Table 6: Total Chi-square value of different types of effects of noise obtained from three noise level ranges and five responds.

\begin{tabular}{|c|c|c|}
\hline Types of effects & Total Chi-square value & $\begin{array}{c}\text { Relationship between the types of } \\
\text { effects at different proposed noise } \\
\text { level ranges and answers P } \leq 0.05\end{array}$ \\
\hline headache & 18.965 & Significant \\
\hline dizziness & 13.942 & Not significant \\
\hline disturbs their peace of mind & 20.716 & Significant \\
\hline nervousness & 31.701 & Significant \\
\hline stressful & 34.246 & Significant \\
\hline speech interference & 26.654 & Significant \\
\hline insomnia & 42.708 & Significant \\
\hline
\end{tabular}

Also respondents were asked about reaction against industrial noise, they asked "Do you want to move to a quieter work" and asked "Do you consider that the noise in your factory is dangerous". It is shown in (Fig. 5) that $97.78 \%$ of respondents said that they like to move to a quieter work and $2.22 \%$ don't like to move to a quieter work. $83.33 \%$ of respondents said that they consider that the noise in their industrial is dangerous, $12.22 \%$ said that is not dangerous and $4.44 \%$ of workers said that they do not know if the noise in their industries is dangerous or not. 


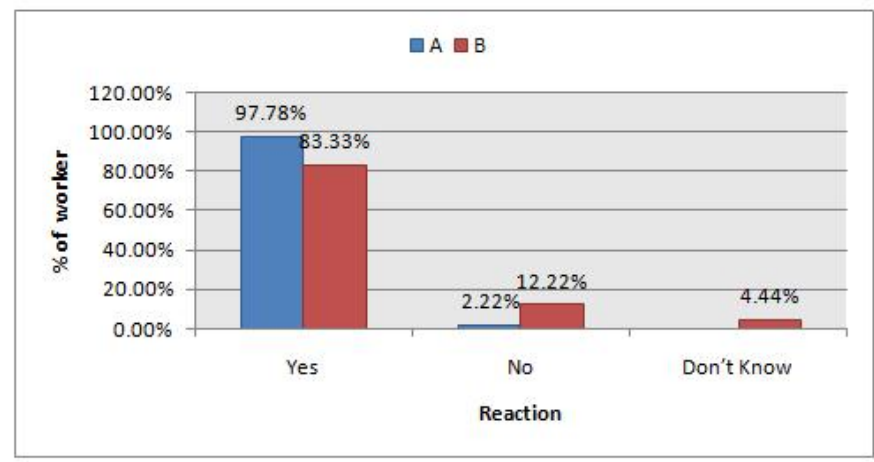

Fig. 5: Reactions of respondents against industrial noise.

\subsubsection{Effect of noise in ear and ear protection equipment (EPE)}

Effects on ear were considered significant. When the workers asked about effect of noise on their ears, $65.56 \%$ of workers stated that noise causes "hearing impairment and harms their hearing or pain in their ears" and $34.44 \%$ responded that it "gives them ringing in ears drum". When the workers asked how to protect themselves from hearing loss, in all industries the majority of them know how to protect their ears, but only $10 \%$ of them were used EPE and the others said they are not used EPE, the reasons for not using EPE are: 17.78\% feel uncomfortable, $21.11 \%$ due to negligence, $8.89 \%$ do not know why they are not used and $42.22 \%$ said management did not provide EPE at work place (Fig. 6).

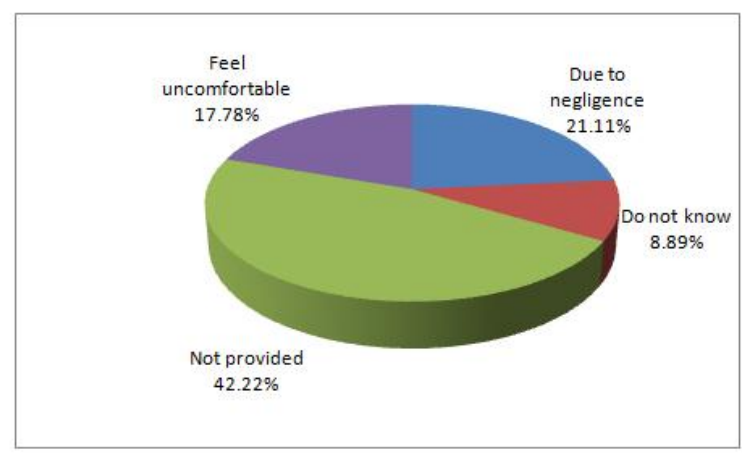

Fig. 6: Reasons for not using EPE at work place.

\section{Conclusion}

Industrial noise exposure has been identified as a very obvious danger especially in small and hand tool industries which are still not mechanized. During our measurements it has been determined that the noise levels in the majority industries are exceeds the maximum (OSHA) exposure limits.

According to results of the questionnaire applied to the all workers in all industries:

1. Majority of workers in the industries are annoyance from the noise in their workplaces.

2. Mostly workers are of little education even under primary, primary and intermediate therefore they are not fully aware of the hazardous effects of noise.

3. There is strong relation between duration of employment years and feeling annoyed, and this relation is statistically important with given Chi-square $=17.407$.

4. Psychological and physiological effects of industrial noise in seven factors (headache, dizziness, disturbs their peace of mind, nervousness, stressful, speech interference and insomnia) was analytic and the answer of these seven variable was in sometimes and always choice options. The Chi-square calculated for each these factors are: 18.965, 13.942, 20.716, 31.701, 34.246, 26.654 and 42.708 respectively.

5. $97.78 \%$ of workers like to move to a quieter work, $2.22 \%$ of them like their factory sound insulated and $83.33 \%$ said that the noise in their industries is dangerous.

6. Almost all the workers are highly exposed to high noise levels compared to (OSHA) limits without proper ear protection, and the majority of them are suffering hearing problems.

\section{References}

[1] Koffeman A, Kerkers A, Cost optimal reduction of noise in large industrial areas - a method to select measures, noise-con 2000. Newport Beach, California; December 03-05, (2000). 
[2] Hayta AB, Effect on Work Environment Conditions Operating Efficiency. J. Commerce Tourism Educ. Fac., 1: 21-41, (2007).

[3] Akhtar H. N., Noise-induced hearing loss in traffic police constables, J Coll Physicians Surg Pak, 6, 265-268, (1996).

[4] Melnick, W. Hearing loss from noise exposure, Handbook of Noise Control, Harris, C. M (Ed.). Mc. Grow Hill, New York, 15, 1,(1979).

[5] Hashmi S. F., Sangeeta S., Berendra Y., Muzammil M.D., Effects of workplace noise on blood pressure and heart rate, Biomedical Research, Ind -medica Journal, 20, 122-126, (2009).

[6] Joshi S. K., Devkota S., Chamling S., Shrestha S., Environmental noise induced hearing loss in Nepal, Kathmandu University Medical Journal, 1, 177-183, (2003).

[7] Jansen G., Effects of noise on human beings. VGB (German) 72 (1), 60, (1992).

[8] Johnson D., Field studies: industrial exposure. J. Acoust Soc. Am 90 (1), 170, (1991).

[9] Alton B., Ernest J., Relationship between loss and noise exposure levels in a large industrial population: a review of an overlooked study. J. Acoust Soc. Am 88 (S1), S73 (A), (1990).

[10] Chedd G., Sound from communication to noise pollution, Science, 211, 1450-1452, (1981).

[11] Peter, G,.Kovalchik., Rudy, J., Matetic., Adam, K., Smith., Susan, B., Bealko, Application of Prevention through Design for Hearing Loss in the Mining Industry. Journal of Safe Research, 39, pp 251-254, (2008).

[12] Rehdanz, K., Maddison, D., Local environmental quality and life satisfaction in Germany. Ecological Economics, 64, pp 787-797, (2008).

[13] Tang, U.W., Wang, Z.S., Influences of urban forms on traffic-induced noise and air pollution; Results from a modelling system. Environmental Modelling Software, 22, pp 1750-1764, (2007).

[14] Driussi, C., Jansz, J., Technological options for waste minimisation in the mining industry. Journal of Cleaner Production, 14, pp 682-688, (2006).

[15] Gundoğdu, O., Gokdağ, M., Yuksel, F., A traffic noise prediction method based on vehicle composition using genetic algorithms. Applied Acoustics, 66, pp 799-809, (2005).

[16] Rao, P.S., Gavane, A.G., Ankam, S.S., Ansari, M.F., Pandit, V.I., Nema, P., Performance evaluation of a green belt in a petroleum refinery: a case study. Ecological Engineering, 23, pp 77-84, (2004).

[17] Guasch, O., Magrans, F.X., Rodriguez, P.V., An inversion modelling method to obtain the acoustic power of the noise sources in a large factory. Applied Acoustics, 63, pp 401-417, (2002).

[18] Sadan, A.A., Onyeonwu.,Ayorinde, E.O., Ogisi, F.O., Community attitudinal noise survey and analysis of eight Nigerian cities. Applied Acoustics, 49, 49-69, (1986).

[19] Schultz, T.J., Synthesis of social surveys on noise annoyance. Journal of Acoustics Society of America, 64, pp 377-465, (1978).

[20] Pachpande, B.G., Patel, V.S., Patil, R.D., Girase, M.R., Ingle, S.T., Assessment of hearing loss in school 32 teachers and students exposed to highway traffic noise pollution. Journal of Ecophysiology and Occupational.Health, 5(1\&2), pp 123-126, (2005).

[21] Yildirim, I.; Kilinc, M.; Okur, E.; InancTolun, F.; Kilic, M. A.; Kurutas, E. B.; Ekerbicer, H.C., The effects of noise on hearing and oxidative stress in textile workers. Ind. Health, 45 (6), 743-749, (2007).

[22] Keipert, J. A., The harmful effects of noise in a children's ward. J. Paediatr. Child Health, 21 (2), 101-103, (2008).

[23] Prasher, D., Estimation of hearing damage from noise exposure, World Health Organisation and European Centre for Environment and Health Report on the Technicalmeeting of exposure-response relationships of noise on health, Bonn, Germany. pp 17-19, (2003).

[24] Stansfeld, S., Matheson, P., Noise pollution: non-auditory effects on health. British Medical Bullatin, 68, pp 243-257, (2003).

[25] Ouis, D., Annoyance from road traffic noise: a review. Journal of Environmental Psychology, 21, pp 101-120, (2001).

[26] Langdon, F.J., Noise nuisance caused by road traffic in residential areas: Part I and II. Journal of Sound and Vibration, 47, pp 24382, (1976).

[27] Lakhwinder P. S., Arvind B., Kishore K. D., Occupational exposure in small and medium scale industry with specific reference to heat and noise. Noise and Health, 12(46), 37-48, (2010).

[28] Occupational Safety and Health Administration, US Department of Labor. Hearing Conservation, OSHA 3074, 2002.OSHA, electronic publication at: http://www.osha.gov/index.html, (2004).

[29] Dana N. A. I., Health Effects of Occupational Noise Exposure in the Range (90 - 110) dB(A) Especially on Blood Oxygen Saturation of Workers in Selected Industrial Plants, master thesis, An-Najah National University, Nablus, Palestine, (2012).

[30] Davies HW, Teschke K, Kennedy SM, Hodgson MR, Hertzman C, Demers PA., Occupational exposure to noise and mortality from acute myocardial infarction. Epidemiology 16, 25-32, (2005).

[31] Rai RM, Singh AP, Upadhyay TN, Patil SKB, Nayar HS, Biochemical effects of chronic exposure to noise in man. Int Arch Occup Environ Health 48, 331-7, (1981).

[32] Montgomery, D.C., Runger, G.C., Hubele, N.F. “Engineering Statistics”.3rd edition. New Jersey, USA: John Wiley and Sons, (2003). 